\title{
Reaction of Mentors and Mentees in the Native Speaker Programme of a Rural Primary School in Malaysia: A Phenomenological Study
}

\author{
Mei Yun Ong ${ }^{1} \&$ Siew Eng Lin ${ }^{1}$ \\ ${ }^{1}$ School of Educational Studies, Universiti Sains Malaysia, Penang, Malaysia \\ Correspondence: Mei Yun Ong, School of Educational Studies, Universiti Sains Malaysia, 11800 Gelugor, \\ Penang, Malaysia. Tel: 60-12-536-2683. E-mail: my_ong@hotmail.com
}

Received: February 11, 2015 Accepted: July 11, 2015 Online Published: August 18, 2015

doi:10.5539/ass.v11n22p51 URL: http://dx.doi.org/10.5539/ass.v11n22p51

\begin{abstract}
This phenomenological study investigated the reaction of the mentors and mentees in the Native Speaker Programme implemented in a rural primary school in Malaysia from 2011 to 2013 in terms of 1) programme objectives, 2) time frame, 3) motivation of the mentors and mentees and, 4) cooperation given throughout the programme. Three mentors and two mentees were interviewed to obtain their responses; and they were observed during classroom teachings and workshops. The results from the interviews and observations were triangulated to provide a comprehensive picture of the findings. It was found in the results that a strong mentoring relationship and effective communication are crucial to convey the essential information at the top-down level and to ensure that objectives are achieved. The mentoring relationship would subsequently have the bearing on their levels of motivation and to work collaboratively.
\end{abstract}

Keywords: native speaker programme, mentor, mentee

\section{Introduction}

In 2009, the Minister of Education of Malaysia announced that the Upholding Bahasa Malaysia and Strengthening the English Language policy would be implemented to replace the Teaching of Mathematics and Science in English policy to ensure that each child can master both Malay and English languages fluently (Ministry of Education, 2012). In order to support the new policy, the Ministry of Education (MOE) of Malaysia decided to employ native English speakers as mentors to assist in building the capacity of primary school English teachers and lecturers at teacher training institutions in this country. The Native Speaker programme was implemented from 2011 to 2013 in selected primary schools and teacher training institutions nationwide.

Upon the announcement of the decision to engage native English speakers into the education system, some significant points regarding the reason they were brought into this country were raised in the report on a forum held at the $19^{\text {th }}$ MELTA (Malaysian English Language Teaching Association) International Conference in 2010. According to MELTA (2010), one of the points highlighted was the inability to recognize the Malaysian English language teachers' set of skills, knowledge and teaching qualifications. The dependence on the foreign English language teachers and the ministry's inability to recognize the local Malaysian expertise may result in negative reaction in embracing the Native Speaker programme. Moreover, there were concerns about how viable the programme was going to be after it is implemented in various schools and after the mentors leave the country (MELTA, 2010). There were also worries on the effects to the Malaysian English language teachers' morale, motivation and self-esteem (MELTA, 2010). In the running of the Native Speaker programme, local English teachers may feel that they would be looked upon as second best when they are compared to the native English speaker.

It is important for the mentors and mentees to overcome socio-cultural differences that may challenge cross-race mentoring and hinder them to work together. Hansmann (2003) stated that mentors need to understand the cultural characteristics in the area in order to be helpful and effective. Besides that, the status of the English language as the second language in Malaysia may require mentors to be bilingual (MELTA, 2010) so that they may relate better with the students in rural areas who usually speak their mother tongue; and to empathize with the uphill tasks that the ESL teachers face.

This phenomenological study provides an account of the reactions, most importantly the experiences, of the mentors and mentees of a particular primary school involved in this programme. Therefore, this study investigates 
the reactions of the mentors and mentees in four different aspects which are their feedback on the programme objectives and content, time frame, their level of motivation and the cooperation throughout the running of the Native Speaker programme.

\section{Literature Review}

\subsection{Upholding Bahasa Malaysia and Strengthening the English Language Policy}

The Upholding Bahasa Malaysia and Strengthening the English Language policy replaced the Teaching of Mathematics and Science in English policy in stages. The policy restored the Malay language as the medium of learning and teaching Science and Mathematics because studies revealed that students found it difficult to learn Science and Mathematics in the English language especially in the rural areas. This would allow teachers and students to adapt to the policy change. All Malaysian schools have the choice to use English language or the mother tongue to teach Science and Mathematics during the transitional period. This policy ensures all national primary and secondary schools use the Malay language as the medium of communication and instruction, and students would become proficient in the Malay and English languages (Ministry of Education, 2012).

\subsection{The Native Speaker Programme in Malaysia}

The Ministry of Education (2012) stated that Key Performance Indicator (KPI) for the Native Speaker Programme is to increase the capability and competence of English language teachers. The expatriates who were placed in primary schools are known as mentors were required to assist the English language teachers in the areas specified by the Ministry of Education. Those particular areas are planning and coordinating professional development programmes; preparing and executing workshops, training sessions and relevant programmes within clusters and zones; cooperating with other mentors from different clusters and zones to organize activities; planning and organizing co-curriculum activities; providing assistance and support activities during teaching and learning in the classrooms; conducting appropriate action research; working with ministry officials to assess the programme; and creating a group of teachers as potential master trainers.

Throughout the three years of the programme, the school which participated in this phenomenological study had been under the tutelage of three mentors, of whom one was transferred to another cluster and another left the programme due to personal reasons. In each contract year of the programme, there were four KPIs as stated by the vendor that the mentor has to achieve: every teacher has to obtain 75 hours of professional input through different methods such as individual mentoring at least once a fortnight, in situ mentoring and training, cluster and zone levels training; demonstrate development in classroom teaching and learning based on two classroom observation in a year; teachers need to show progress in the English language proficiency; and to develop a sufficient amount of quality and suitable resources in electronic or print form that can be used inside and outside the classroom.

\subsection{Kirkpatrick's Model of Evaluation}

The main focus of this study is to gain insights of the reactions given by the mentors and mentees in this programme. Befitting the purpose of this study, the researcher selected the Kirkpatrick's evaluation model, developed by Donald Kirkpatrick in the 1950s. There are four levels in this model which are: Level 1 - Reaction, Level 2 - Learning, Level 3 - Behaviour and Level 4 - Results (Kirkpatrick \& Kirkpatrick, 2005). This study focuses on the first level in the model that basically deals how the participants react to a programme (Kirkpatrick, 1998) because it can make or break the running of a programme. In accordance to Naugle et al. (2000), one of the ways to benefit from a programme is for the participants to have pleasant feelings towards it. Kirkpatrick and Kirkpatrick (2007) suggested various forms that they developed, and the researchers' job is to "borrow or develop" one of their own. Therefore, the researcher adapted four aspects to investigate the first level in the Native Speaker programme, which are programme objectives and content, time frame, motivation and cooperation. These are outlined in the following subsections.

\subsubsection{Programme Objectives and Content}

Kirkpatrick (1998) suggested three considerations to determine the objectives of a programme which are, the results to be accomplished in a programme, the kind of behaviours needed to achieve the results, and the set of knowledge and skills that the programme wants the participants to attain. Kirkpatrick (1998) has cautioned that participation in a programme may be scarce if it was implemented on a volunteerism basis. In this case, only selected primary schools were selected to participate in the Native Speaker programme, and it basically meant that the mentees in those schools are obligated to join the programme. 


\subsubsection{Time Frame}

Kirkpatrick (1998) mentioned that the trainees, bosses, and conditions for learning need to be considered in planning a favourable timetable. Kirkpatrick and Kirkpatrick (2007) remarked that the best schedule for a programme to be carried out is to meet the participants' needs and convenience instead of the instructors' desires. The participants' stance towards a programme may be negative if they attend a training programme at an unsuitable time.

\subsubsection{Motivation}

The selection of effective trainers is crucial to keep the participants motivated in a training programme (Kirkpatrick \& Kirkpatrick, 2007). The trainers need to possess qualifications similar or higher than the mentees, the knowledge on subject matter, have the capability to facilitate a workshop discussion and have interpersonal skills to build relationship with the participants (Kirkpatrick, 1998). A theory linked to motivation is Bandura's Social Cognitive Theory where it suggests that people are driven by inner forces and external factors. Bandura (1986) defined the importance of self-efficacy as it form of motivation that helps to determine choices to be made; and the basis of self-efficacy is encouragement.

\subsubsection{Cooperation}

Malaysian English language teachers may view that having a new individual from a foreign country entering a local primary school in either a positive or negative light. Some may feel that they are looked down on, the presence of a mentor may be invasive or some may welcome the mentor warmly. In similar scenario in Japan for instance, a group of Japanese Teacher of Language (JTL) have varied reactions when foreign English language teachers known as Assistant Language Teacher (ALT) arrived in the schools under the Japan Exchange and Teaching (JET) Programme. McConnell (2000) categorized the types of reactions of JTLs into three, which are "the enthusiasts, the detractors and the ambivalent" JTLs. ALTs responded that they prefer to work with the enthusiasts who are more positive and have the desire to experiment with new teaching styles and improve their language skills.

\section{Methodology}

\subsection{Participants}

There were five participants in this study, three mentors and two mentees of which their experiences in the Native Speaker programme were recorded. Pseudonyms were used throughout the study to ensure confidentiality of the mentors and the mentees of the rural primary school.

\subsection{Data Gathering Methods}

The phenomenological approach was chosen because it allowed the researcher to encapsulate and depict the way a phenomenon is experienced by people, the way they perceive it, feel and think about it, form an opinion on it, remember it, construct meaning out of it, and converse with people about it (Patton, 2002). Bogdan and Taylor (1975) mentioned that a phenomenological researcher has to view things in the participants' perspectives to gain understanding and meanings of their behaviour. In accordance to Bogdan and Biklen (2007), researchers should try to put themselves into the other person's shoes to better understand the meaning of events in given situations.

The three major data gathering methods utilised in this study were observation, interview and collection of documents. The researcher drew out a checklist for the formal observation used in this study that was adopted from the Malaysian Education Quality Standard. The semi-structured interview was adopted in this phenomenological study as suggested by Smith and Osborn (2008). Concentration was given to interview the mentors and mentees after class observations and workshops; and get responses to answer the research question. The interview questions were formulated according to the objectives stated by the MOE regarding the Native Speaker programme, and checked by content experts to ensure the validity and reliability.

\subsection{Data Analysis}

In this study, the data collected were primarily from observations and interviews. The data from interviews were transcribed and observations were recorded as field journals. The researcher had observation field journals, interview transcripts and documents to be studied in the data reduction phase. The data reduction process was done after the data was gathered into particular "groups" or themes. The researcher carried out the process of coding, clustering, and writing notes to highlight themes that were relevant to this study. The data were also cross checked with the other data collected. This was an ongoing process until the researcher achieved the saturation point in the study (Merriam, 1998). 


\section{Results}

\subsection{Theme One: Achieving the Programme Objectives}

With regards to the programme objectives, the mentors agreed that they are achievable and the mentees have what it takes to achieve them. The KPIs for the mentors were not stated clearly at the beginning of the programme, until it was clarified when the programme progressed during the years. The initial reaction given by the mentees when interviewed was they regarded the programme as an inconvenience. This is because the mentees were not given prior notice when it was implemented. The mentees were uncertain about the relevance of the programme.

As mentioned earlier, mentors had to conduct workshops and training programmes to allow the mentees to achieve the required 75 hours in each contract year. Workshops arranged based on the dates given by the mentees and according to the mentor's availability were conducted by the mentors, usually on Tuesday afternoons after school hours at the Teachers' Activity Centre. The topics of the workshops were predominantly determined by the mentors as they deemed fit for their mentees, and the mentees sometimes suggested topics that they wanted the mentors to address. One mentor said that his mentees utilized the suggested activities from workshop discussions and saw improvements in the mentees' way of teaching. The mentees responded that some of the topics done in workshops were beneficial as the information supplied to them was refreshing and it helped them to deliver their teaching lessons better. However, some of the mentees have already attended similar courses prior to the Native Speaker Programme and felt that these courses did not help much. The mentees further commented that a mentor did not deliver applicable and relevant topics for the workshops. They questioned the content of the topic given and how it could be taught to the primary school students, and the mentor insisted it was necessary despite the mentees' objection. Throughout the three-year programme, the mentors from other clusters and zones had come together to organize a centralized workshop for the mentees of the participating schools in a selected venue. The mentors and mentees were part of the knowledge-sharing project.

On the other hand, there were no action researches done as the mentors and mentees mentioned that they were unaware of this criterion of the programme and thus was not pursued further. When the mentors were asked on how often they work with the officials to assess the programme, the meetings with the officers were held when they were required to discuss important subject matters and those meetings were kept to the minimum. From the interviews done, it dawned to the researcher that the District Education Department (DED) officers did not place much importance on this programme as mentors gave feedback that the planned projects for non-participating schools were postponed and cancelled when preparations were done. The DED was not aware that the mentees are improving in their teaching and pegagogical skills, because it was not clear to the mentors and mentees of this Native Speaker programme whether they were of primary importance to the DED.

Furthermore, more information and clear benchmarks have to be outlined to the mentors, mentees and to the schools, because upon their arrival, the Head Teacher did not know what the mentors were doing. The mentors believed that the mentees are well-prepared and capable of executing the responsibilities to be master trainers if this programme is continued. In order to be an effective programme, mentees should be given a focused job, without being overwhelmed by other responsibilities.

\subsection{Theme Two: Suitability of the Duration of the Programme}

In each contract year, the mentees have to fulfill 75 hours of professional development for 11 months in 2011 and 2012, and 55 hours for nine months in 2013. The mentees can achieve the target hours through workshops attendance, formal, and informal observations by the mentor, team teaching, and micro teaching with the mentor, material building, - and planning of English lessons and activities. One of the main ways to fulfill the required hours was attending workshops. However, the mentees expressed that they could not always be present for the workshops because they were preoccupied with school activities, meetings, clerical work, and co-curricular activities. One of the mentees also expressed that sometimes the workshop time coincided with the after school classes that he conducted for his students. When the mentees did not attend workshops, the mentors had to go to the schools to meet up with the mentees to help them fulfill the specified hours.

A mentor remarked that the hours were achievable, however it may burden the mentees especially those in the rural areas, because there is a limited number of teachers to teach the English subject. The mentees cannot participate at the level the programme requires and at the level where he would like to see due to the amount of workload that the mentees have in school. Another difficulty that the mentors faced in achieving the hours is the inconsistent number of mentees provided to them in schools, and this impeded their efforts to achieve the required amount of hours. There is a limit to the mentors' time and ability to replace the mentees' missed hours when they cancelled appointments at the eleventh hour as the mentors do have other schools to visit. Therefore, 
the mentors would like the mentees to honour the time arrangements, and the mentees could be more accountable to their mentors.

\subsection{Theme Three: Motivation and the Drawbacks}

The mentors and mentees noted that the motivation which they experienced depended largely on each other's support, response and participation. They corresponded that motivation came through words of encouragement, showing support and building confidence. On the other hand, the feeling of discouragement was expressed through the feeling of being dejected despite efforts given and mentees cancelling pre-arranged meetings at the last minute. The mentees had contrasting experiences with the different mentors. They were more motivated when mentors displayed understanding towards the amount of workload that they had to juggle with and did not feel pressured when this programme was implemented. The mentors also felt the positive atmosphere when the mentees reciprocated with their attendance in workshops, building materials for classroom purposes and executing mini projects in school such as creating an English hut and a reading corner in class.

A dispiriting point for the mentors was the overlap or change of instructions from the DED as mentioned in Section 4.1 regarding cancelled projects planned. The mentors mentioned that the lack of communication and meetings between the mentors and the officers in the department was discouraging.

In contrast to other mentors, a particular mentor rarely gave credit to the mentees' capabilities which caused them to be disheartened. As time went on, there were lesser participation and interaction between them as the mentees felt that they were shot down though efforts were made. The mentor's insistence to get things done without considering the workload that the mentees had to shoulder bore negative consequences to the relationship. An example of a case that occurred was when the school hosted a cluster level English language competition. The mentor was notified to postpone his school visit, but he arrived in school hours before the event and insisted the mentees to do what they were told. He also had an argument with the Head Teacher and Senior Assistant ahead of the competition. The mentor's inconsideration caused discord and left the mentees disappointed by his treatment. As a result of this poor communication skill, the mentors and mentees have to develop good interpersonal skills, a higher level of empathy of their counterparts' job and encourage one another frequently.

\subsection{Theme Four: Cooperation and the Drawbacks}

On the subject of cooperation, the mentors and mentees expressed cooperation through making adjustments and ability to work with someone. After observing a lesson during the mentor's visit, he would discuss how the mentees fared and feedbacks were given. The mentor suggested that he would conduct a demonstration lesson on how they would teach the same lesson in a different way. The mentors and mentees would also work hand in hand to have team teaching in the classroom. Before doing so, meetings were held to designate each other's parts for the planned lesson. Other than conducting lessons in classroom, the mentors participated in extra-curricular activities such as going on school trips and gave motivational talk to students. Some mentors helped out the mentees after school hours to train students for English language competitions.

One mentor in this study did not carry out any demonstration lessons throughout the year although requests were made by the mentees. The feedbacks and comments given by the mentor after his initial classroom observation were mostly negative. The mentor also refused to help in organizing extra-curricular activities and declined to attend them. Moreover, the mentor criticized one of the mentees' accent and his comments led to a heated argument. Cooperation was lacking between this mentor and the mentees when critical remarks were exchanged at some points due to disagreements and unwillingness to listen and to accept opinions. As the mentees have had experiences with other mentors, they had a set of expectations of how this mentor should carry out his duty in this programme. Thus, tolerance and discussion are vital in ensuring cooperation exists and to allow the mentors and mentees to work together.

\section{Discussion}

From the findings, it is discovered that there is inadequate communication and clarification of the programme objectives between the policy makers, the mentors and mentees. Guo and Sanchez (2005) found that there is a relationship between communication and the effective performance of an organization. Scott (2005) emphasized the importance of clarifying the expectations by providing relevant feedback; and to communicate clearly and frequently by delivering as much information as possible. In this Native Speaker Programme, there is a need for a two way communication between the MOE and the Head Teachers of the schools involved because upon the mentors' arrival, the Head Teacher in the school of this study was left in the dark. It may be more helpful if the MOE or DED informed the Head Teachers about this programme and its objectives. When the school and the 
mentors have a mutual understanding, there may be a higher possibility that the objectives set will be achieved.

The mentees felt the time frame would be ample if 'good' mentors can provide them with the knowledge that they need. The mentees felt that it was a waste of time to attend workshops because they could not gain anything beneficial. From the findings, the mentors agreed that the hours were achievable, but mentees are preoccupied with their duties in schools that hindered them from achieving the target hours. The researcher would like to suggest that the mentor and mentees to be given extra time to meet and possibly releasing them from extra duty so that they can give priority and commitment to the Native Speaker Programme. The mentors could be given a consistent and suitable number of mentees in order for them to meet the mentees personally because mentors placed in bigger schools were overwhelmed by the number of English language teachers.

Pintrich and DeGroot (1990) researched that individuals with higher self-efficacy tend to be more motivated on a given task. The findings depict that the mentees were more motivated when they were under the guidance of understanding mentors and were less motivated with another due to the lack of affirmation received. The mentees need to be reassured that they are capable to carry out their teaching duties in school and in restoring their confidence in the English language. The mentors too, need to experience the feeling of worthiness by the mentees through constant support and appreciation in their effort in assisting them.

According to Appelbaum, Ritchie and Shapiro (1993), mentoring is an interpersonal relationship built on trust. A good relationship has to be built in mentoring and communication needs to be enhanced that is core in this mutual bond. Lee et al. (2006) stressed on the importance of communication and sharing expectations with each other. The mentor-mentee relationship formed at the initial stage was crucial because it has an immense influence on the motivation and cooperation.

\section{Conclusion}

The objectives of the Native Speaker programme stated by the MOE were partially achieved, which may be due to the lack of effective communication of important information from the top-down level. There may be room for improvement for the DED and the mentors to have constant interaction to gauge the mentees' accomplishment in the areas specified by the MOE. This three-year programme was adequate for the mentors to carry out their responsibilities and would like to see that the mentees play an active role in keeping appointment times. As for the mentees, the length of three years could be tedious for them in addition to school duties and to fulfill the programme's requirements. The mentors' and mentees' motivation strongly depended on extrinsic motivation such as words of encouragement and the ability to display understanding towards each other's duties. Cooperation can be closely related to motivation, because when there is a positive reinforcement, there would be a higher possibility of collaborating successfully.

The Native Speaker programme was successful at certain levels when the mentors and mentees felt comfortable with each other and managed to build a healthy mentoring relationship. When this foundation is strong, many of the programme objectives set can be achieved and the mentors and mentees would be able to do more than what the MOE has targeted for this programme. Then again, the efforts to achieve objectives may be impeded when the core relationship is fragile and when there is discord. The accomplishment of any programme relies strongly on the mentors and mentees who participate in it. Whilst individual personalities may differ, a lesson to be learnt is to accept those differences and work hand in hand to ensure the success of the programme.

\section{References}

Appelbaum, S. H., Ritchie, S., \& Shapiro, B. T. (1994). Mentoring revisited: An organizational behaviour construct. Journal of Management Development, 13(4), 62-72. http://dx.doi.org/10.1108/0262171 9410057078

Bandura, A. (1986). Social foundations of thought and action. Englewood Cliffs, New Jersey: Prentice-Hall.

Bogdan, R. C., \& Biklen, S. K. (2007). Qualitative research for education: An introduction to theories and methods (5th ed.). USA: Pearson Education, Inc.

Bogdan, R., \& Taylor, S. (1975). Introduction to qualitative research methods. New York: Wiley.

Guo, L. C., \& Sanchez, Y. (2005). Workplace communication: Organizational behaviour in health care by Nancy Borkowski (pp. 77-110). Sudbury: Jones and Bartlett Publications.

Hansmann, C. A. (2003). Reluctant mentors and resistant protégés: Welcome to the "real" world of mentoring. Adult Learning, 14(1), 14-16.

Kirkpatrick, D. L. (1998). Evaluating training programs: The four levels (2nd ed.). San Francisco, CA: Berrett-Koehler Publishers, Inc. 
Kirkpatrick, D. L., \& Kirkpatrick, J. D. (2005). Transferring learning to behaviour: Using the four levels to improve performance. San Francisco, CA: Berrett-Koehler Publications, Inc.

Kirkpatrick, D. L., \& Kirkpatrick, J. D. (2007). Implementing the four levels: A practical guide for effective evaluation of training programs. San Francisco, CA: Berrett-Koehler Publications, Inc.

Lee, S. H., Theoharis, R., Fitzpatrick, M., Kim, K. Y., Liss, J. M., Nix-Williams, T., ..., Walther-Thomas, C. (2006). Create effective mentoring relationships: Strategies for mentor and mentee success. Intervention in School and Clinic, 41(4), 233-240. http://dx.doi.org/10.1177/10534512060410040601

McConnell, D. L. (2000). Importing diversity: Inside Japan's JET program. Los Angeles, California: University of California Press.

MELTA. (2010). A report on the forum "To go or not to go native: The role of native speaker teachers and trainers in second and foreign language teaching". Retrieved October 15, 2012, from http://www.melta.org.my/images/MELTA_Native_Speaker_Forum_Report_2010.pdf

Merriam, S. B. (1998). Qualitative research and case study applications in education. San Francisco: Jossey-Bass.

Ministry of Education. (2012). Frequently asked questions. Retrieved January 10, 2015, from http://www.moe.gov.my/en/soalan-lazim-view?id=150\&cat=28\&keyword=\&page $=1 \&$

Naugle, K. A., Naugle, L. B., \& Naugle, R. J. (2000). Kirkpatrick's evaluation model as a means of evaluating teacher performance. Retrieved September 5, 2014, from http://www.highbeam.com/doc/1G1-6696 0815.html

Patton, M. Q. (2002). Qualitative evaluation and research methods (3rd ed.). Thousand Oaks, London: SAGE Publications.

Pintrich, P. R., \& DeGroot, E. V. (1990). Motivational and self-regulated learning components of classroom academic performance. Journal of Educational Psychology, 82(1), 33-40. http://dx.doi.org/10.1037/00220663.82.1.33

Scott, J. T. (2005). Managing the new frontiers: An introduction to the fundamentals. Florida: Management Education Services.

Smith, J. A., \& Osborn, M. (2008). Interpretative phenomenological analysis. In J. A. Smith (Ed.), Qualitative psychology: A practical guide to research methods (2nd ed., pp. 53-80). London: SAGE Publications.

\section{Copyrights}

Copyright for this article is retained by the author(s), with first publication rights granted to the journal.

This is an open-access article distributed under the terms and conditions of the Creative Commons Attribution license (http://creativecommons.org/licenses/by/3.0/). 